M. LOTZ AND F. C. BARTTER: STONE DISSOLUTION WITH D-PENICILLAMINE IN CYSTINURIA
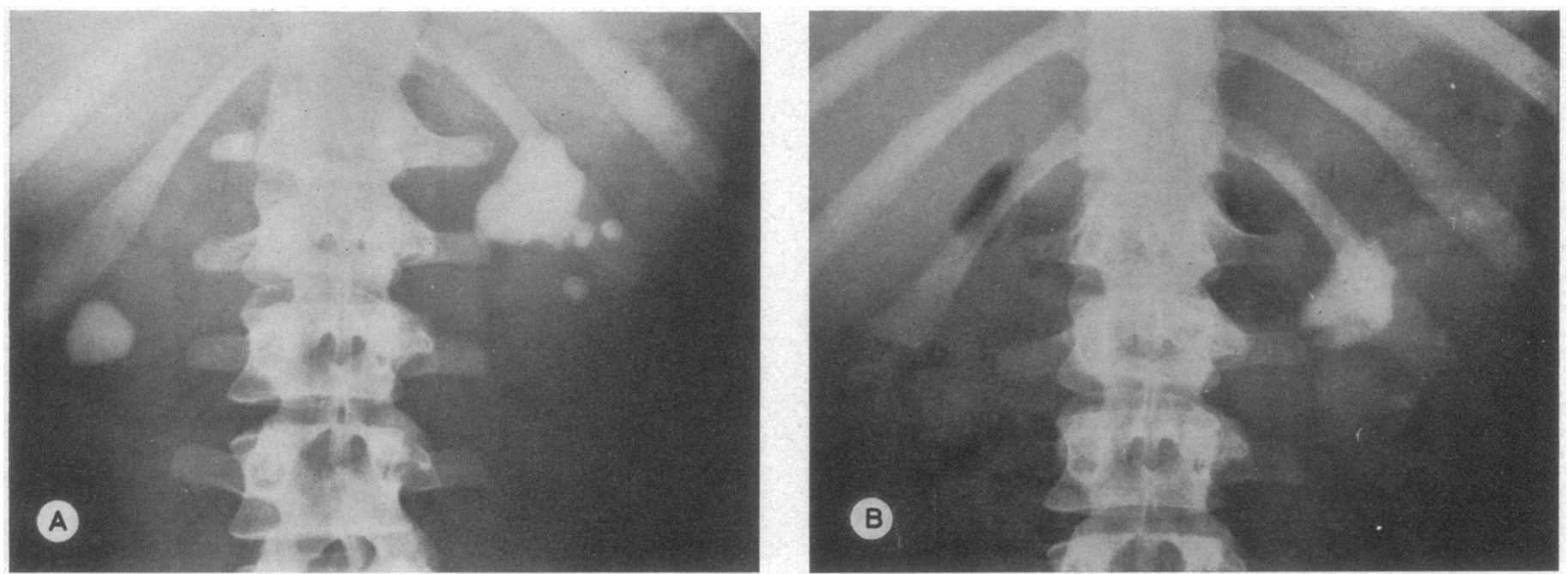

Fig. 1.-Case 1. (A) 8 July 1964 : prior to D-pen. (B) 15 September 1965 : the right stone had been removed surgically. Duration of therapy - two and a quarter months.
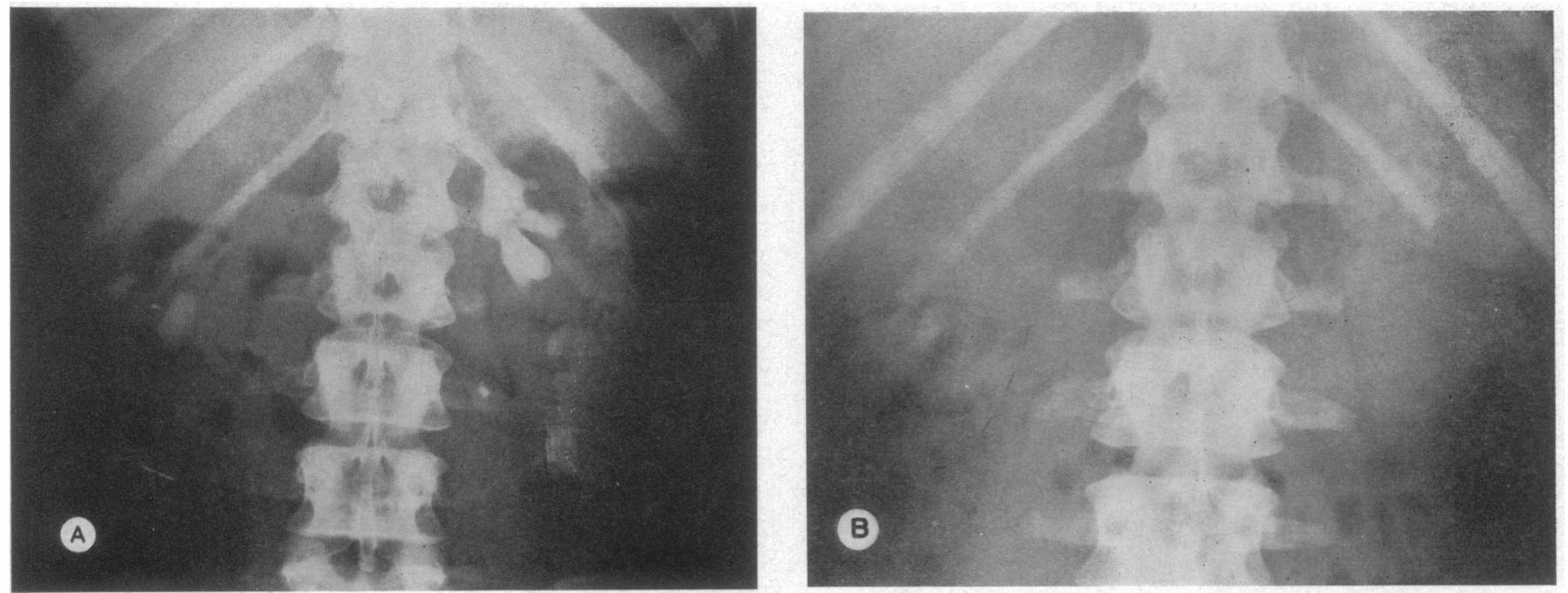

Fig. 2.-Case 2. (A) 12 November 1964 : prior to D-pen. (the longitudinal shadow underneath the left renal area is an artifact). (B) 14 June 1965 : the left stone has been removed surgically. Duration of therapy-six and a half months.
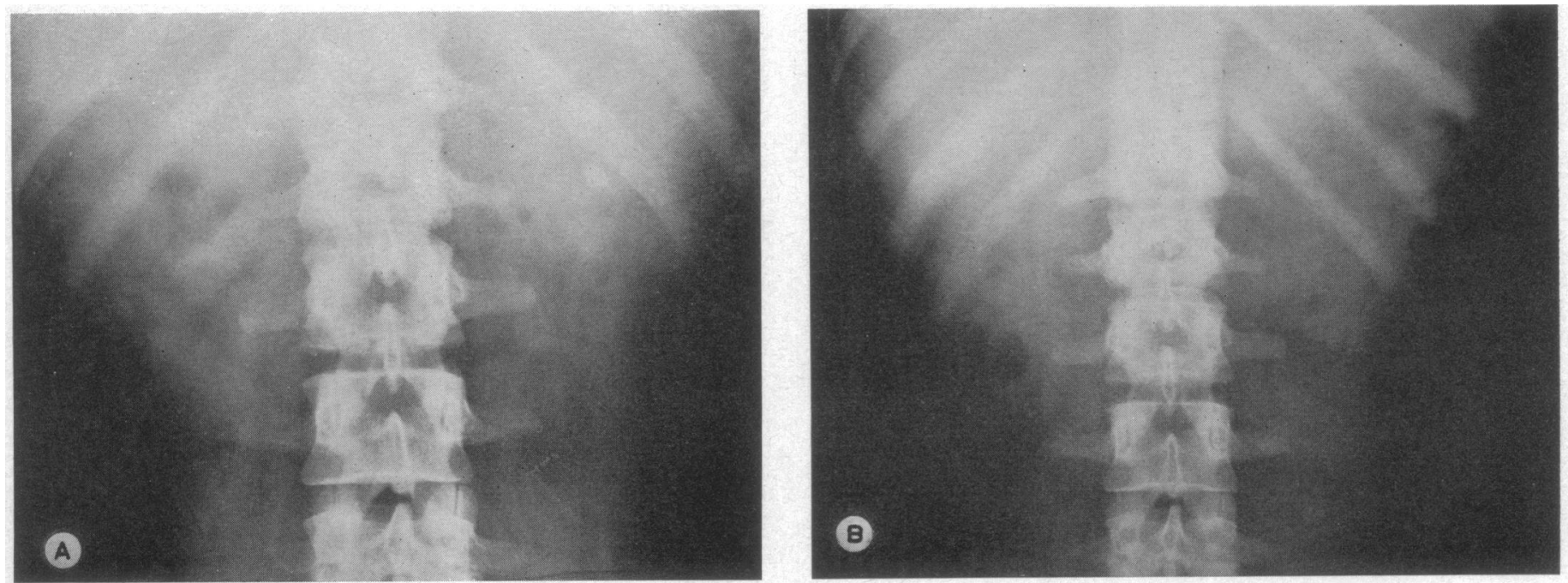

Fig. 3.-Case 4. (A) 19 February 1965: prior to D-pen.

(B) 2 June 1965. Duration of therapy-three and a half months. 


\title{
Stone Dissolution with D-Penicillamine in Cystinuria
}

\author{
M. LOTZ,* M.D. ; F. C. BARTTER, $†$ M.D.
}

[With Special Plate]

Brit. med. F., 1965, 2, 1408-1409

Over the past several years we have reported on the favourable use of $\mathrm{D}$-penicillamine ${ }^{1}$ (D-pen.) in 14 patients with cystinuria whose disease could not be controlled by the conventional therapeutic regimen of forced fluids, alkali, and restriction of dietary methionine (Lotz and Potts 1964 ; Lotz et al., 1965a; Bartter et al., 1965). Similar reports by others have also appeared (Crawhall et al., 1963, 1964).

In this report we wish to offer recent evidence of significant stone dissolution that we have now observed in four of our patients with refractory cystinuria after the addition of D-pen. to the conventional therapeutic programme. Preliminary mention has been made elsewhere of two of these cases (Lotz et al., 1965c).

\section{Patients Studied}

All patients had cystinuria documented by stone analysis and urinary amino-acid studies. Disease had progressed in all despite adherence to fluid and alkali therapy. In Cases 1, 3, and 4 even the most strict adherence to fluid and alkali therapy, together with restriction of dietary methionine, did not prevent growth of stones. Because these patients were judged refractory to conventional management they were referred to us for further investigation and therapy. Brief clinical histories are as follows.

Case 1.-An 18-year-old girl had had three nephrolithotomies for cystine calculi recurring despite good adherence to conventional therapy. She was admitted to hospital in June 1964 with large bilateral renal stones (Special Plate, Fig. $1 \mathrm{~A})$. D-Pen. ( 0.5 g. p.o. q.i.d.) and pyridoxine (50 mg. p.o. q.d.) were begun on 16 July. Right nephrolithotomy was done on 25 August before it was known that D-pen. could effect stone dissolution. Films of residual left renal stone on 15 September showed some dissolution of stone (Special Plate, Fig. 1 B), but left nephrolithotomy was necessary on 6 October because of obstruction and pyelonephritis. She remained stone-free at the time of writing.

Case 2.-A 26-year-old woman had had two nephrolithotomies for cystine calculi recurring despite close adherence to conventional therapy. She was admitted to hospital on 11 November 1964. D-Pen. (0.5 g. p.o. q.i.d.) and pyridoxine $(50 \mathrm{mg}$. p.o. q.d.) were begun on 26 November. The $x$-ray picture prior to D-pen. therapy is shown in Fig. $2 \mathrm{~A}$ (Special Plate). Left nephrectomy was carried out on 5 January 1965 for infected, non-functioning kidney. $X$-ray examination in June 1965 showed significant reduction in size of residual right renal stones after six months' therapy (Special Plate, Fig. 2 B). Urine continued to be infected with pseudomonas, sensitive only to colistin and Mandelamine (hexamine mandelate). In view of stone dissolution a decision was made to defer surgery and continue D-pen. therapy. For suppressive therapy Mandelamine (1 g. p.o. q.i.d.) was given. Urinary acidification was achieved with $\mathrm{NH}_{4} \mathrm{Cl}(2$ g. p.o. q.i.d.). Despite acidity of the urine, urinary cystine continued to be suppressed on D-pen. She was still under treatment at the time of writing.

- Clinical Endocrinology Branch, National Heart Institute, National Institutes of Health. Bethesda, Maryland. Present address: Assistant
Prnfessor of Medicine, Georgetown Medical School, Washington, Prnfessor of Medicine, Georgetown Medical School, Washington,
D.C., and Chief Medical Officer, Georgetown Medical Division, D.C. D.C., and Chief Medical Officer, Georgect

+Chief, Clinical Endocrinology Branch, National Heart Institute, National Institutes of Health, Bethesda, Maryland.

${ }^{2}$ Supplied as Cuprimine by courtesy of Dr. Elmer Alpert, Merck Sharp and Dohme. West Point, Pennsylvania.

- We have recently encountered one patient who could not be desensitized.
Case 3.-A 23-year-old male law student had had multiple operations for renal and bladder calculi despite strict adherence to conventional programme and restriction of dietary methionine. He was admitted to hospital on 17 February 1964 . D-Pen. $0.5 \mathrm{~g}$. p.o. q.i.d.) and pyridoxine (50 mg. p.o. q.d.) were begun in March. $X$-ray examination revealed stone dissolution and disappearance over a nine-month period. He remained stone-free up to the time of writing.

Case 4.-A 37-year-old woman who had had three nephrolithotomies for cystine calculi was referred to us stone-free in 1963. She was maintained stone-free on conventional therapy until 19 February 1965, when $x$-ray examination showed left renal calculus (Special Plate, Fig. 3 A). D-Pen. (0.5 g. p.o. q.i.d.) and pyridoxine (50 mg. p.o. q.d.) were begun on 19 February on an out-patient basis. Serial $x$-ray films showed complete stone dissolution over a period of three and a half months (Special Plate, Fig. $3 \mathrm{~B}$ ). She remained stone-free up to the time of writing.

\section{Discussion}

It is difficult to obtain an accurate estimate of the percentage of patients with cystinuria who do not respond to the conventional therapeutic programme. Dent et al. (1965) report that some $33 \%$ of cases are not improved by hydration and alkali (in small dosages). In our series all the patients referred to us had proved refractory to conventional therapy. In any event such statistics are not of crucial importance in the initial management of a given patient.

Our approach to a new case would be as follows.

(a) In the case of the asymptomatic, stone-free patient with cystinuria of homozygous genotype we would inform the patient of the nature of his disease and advise a high fluid intake " around the clock" to produce a urinary specific gravity of 1010 or less throughout the day.

(b) In the case of the symptomatic patient with either renal stones or repeated passage of urinary gravel we would add to this regimen alkali-usually sodium, potassium citrate, in amounts sufficient to maintain a urinary $p \mathrm{H}$ of 7.4 or higher (usually $20 \mathrm{mEq}$ p.o. q.i.d.). To date we have not encountered systemic alkalosis, hypercalcaemia, or oedema. Sodium bicarbonate can also be used and offers the advantage of tablet form.

(c) In the case of the patient "resistant" to hydration and alkali we would restrict dietary methionine to about $1 \mathrm{~g}$./day or less. This can usually be done with an animal protein intake of $0.5 \mathrm{~g}$./ $\mathrm{kg}$./day. Protein supplementation can be achieved with peanut butter. On this programme we have documented significant reductions in urinary cystine by amino-acid chromatography without evidence of malnutrition.

(d) In the case of the patient in whom all three measures fail, or who finds the discipline of the programme intolerable, we would give D-pen. 0.5 g. p.o. q.i.d. Dosage can be adjusted with the simple test previously described (Lotz et al., 1956b). Pyridoxine, $50 \mathrm{mg} . /$ day, is added to counteract any possible anti-vitamin activity of D-pen. (Jaffe et al., 1964).

With this programme we have invariably been successful in suppressing stone formation. In addition, no instances of drug toxicity have proved severe enough to warrant cessation of D-pen. therapy in any patient. During the first week of D-pen. therapy some $33 \%$ of patients will experience fever, skin eruptions, and malaise. Desensitization has invariably ${ }^{2}$ been 
achieved simply by stopping therapy until symptoms subsideusually in four to five days-and then resuming therapy gradually with increasing doses over several weeks. We have used D-pen. successfully now in two patients with welldocumented histories of penicillin allergy.

Previously it was our belief that $\mathrm{D}$-pen. would be effective only in preventing de novo stone formation or progression of stones already formed. Therefore patients with calculi and pyelonephritis-a complication we not infrequently encounterwere rendered stone-free surgically in order to maximize chances for eradicating infection with selected antibiotics. Our success in dissolving stones in each of these four patients has led us now to be more conservative in recommending operation to patients with nephrolithiasis complicated by pyelonephritis.

So far we have not encountered any patient whose stones proved refractory to dissolution when $\mathrm{D}$-pen. was added to the conventional programme.

Over the last two years five of our patients have decided, quite against our advice, to omit fluids, alkali, and methionine restriction and to continue only on D-pen. All have remained stone-free.

Because D-pen. is thought to suppress cystine most successfully in an alkaline urine we have been hesitant previously to acidify the urine of patients infected with Proteus vulgaris or patients in whom long-term suppressive therapy with Mandelamine was indicated. Our experience in Case 2 indicates that high-acidity of the urine does not interfere with the action of D-pen. Our plan with this patient is to dissolve the stones completely and then attempt a cure of pyelonephritis with appropriate antibiotics.

\section{Summary}

Significant stone dissolution occurred in four patients with cystine calculi when $\mathrm{D}$-penicillamine was added to a previously ineffective conventional therapeutic programme of forced fluids, alkali, and in three cases methionine restriction.

Elective surgery for refractory nephrolithiasis complicated by pyelonephritis should be deferred until a reasonable trial has been made to effect stone dissolution with D-penicillamine.

D-Penicillamine is a highly effective therapeutic agent in cystinuria even when used alone in the absence of the conventional programme.

\section{REFERENCES}

Bartter, F. C., Lotz, M., Thier, S., Rosenberg, L. E., and Potts, J. T. jun. (1965). Ann. intern. Med., 62, 796.

Crawhall, J. C., Scowen, E. F., and Watts, R. W. E. (1963). Brit. med. f., 1, 588. (1964). Ibid., 1, 1411.

Dent, C. E., Friedman, M., Green, H., and Watson, L. C. A. (1965) Brit. med. F., 1, 403.

Jaffe, I. A., Altman, K., and Merryman, P. (1964). Ұ. clin. Invest., 43, 1869.

Lotz, M., and Potts, J. T., jun. (1964). Ibid., 43, 1293.

- - and Bartter, F.'C. (1965a). Milit. Med., 130, 768

-1 - (1965b). Brit. med. F., 2, 521

Holland, J. M., Kiser, W. S., and Bartter, F. C. (1965c). 7.

\title{
Small-bowel Ulceration Induced by Potassium Chloride
}

\author{
W. B. ASHBY,* CH.M., F.R.C.S., F.R.C.S.ED.; JOHN HUMPHREYS, † CH.M., F.R.C.S., F.R.C.S.ED. \\ SINCLAIR J. SMITH, $\ddagger$ M.B., F.R.C.S.ED.
}

Brit. med. F., 1965, 2, 1409-1412

Sporadic cases have been reported from time to time of nonspecific ulceration of the small intestine presenting as intestinal obstruction, perforation, or haemorrhage. Recently it has become recognized that a stenosing ulcer of the small intestine may develop as a rare complication of medication with entericcoated diuretic and potassium chloride tablets.

We report six further cases. All our patients had been taking Hydrosaluric-K (enteric-coated hydrochlorothiazide with potassium chloride). One patient had taken only two tablets. We think it important that the condition be recognized as a cause of intestinal obstruction and perforation in patients taking these preparations. If the symptoms are recognized early enough improvement may follow cessation of treatment.

\section{Case 1}

A man aged 54 was admitted to hospital on 25 May 1964 with a 12-hour history of central abdominal colicky pain and vomiting. For two months he had experienced attacks of abdominal pain, usually occurring one hour after meals. He had been under treatment for malignant hypertension for five years, and had suffered a coronary thrombosis seven months previously. Gastrografin $x$-ray

* Senior Surgical Registrar, Walton Hospital, Liverpool. † Consultant Surgeon, Southport General Infirmary, Lancs. ₹ Surgical Registrar, Royal Alexandra Hospital, Rhyl, North Wales. studies of the small intestine supported a diagnosis of small-intestine obstruction, and laparotomy was advised. At operation on 27 May distended small intestine was traced down to a stricture in the distal ileum. The bowel was collapsed beyond this point. The stricture had the appearance of a smooth ring of narrowing $1-2 \mathrm{~mm}$. wide in the wall of the ileum, and causing almost complete occlusion of the lumen. There was no abnormality in the mesentery, and normal pulsation was observed in the vessels locally supplying the intestine. The stricture was thought to be benign, and, in view of the anaesthetic risk involved, the operation was limited to an enteroanastomosis bypassing the stricture. The patient has had no further attacks of abdominal pain since his discharge from hospital, and has started light work.

Since the diagnosis of malignant hypertension in 1960 this patient has been treated mainly with Inversine (mecamylamine) and Saluric (chlorothiazide). The Saluric was discontinued in favour of Hydrosaluric- $K$ in 1962, and he had been taking two tablets a day, three days a week. He had also been given Darenthin (bretylium tosylate), Serpasil (reserpine), guanethidine, pyridostigmine, and neostigmine for short periods.

\section{Case 2}

A man aged 49 was admitted to hospital on 15 October 1964 with a two-day history of increasingly severe abdominal pain, vomiting, and diarrhoea. He had been admitted to hospital five years, six months, and two months previously on account of abdominal pain, 